\title{
ZnO Films Deposited on Porous Silicon by DC Sputtering
}

\author{
Masato Ohmukai ${ }^{1}$, Takuya Nakagawa ${ }^{2}$, Ayumu Matsumoto ${ }^{3}$ \\ ${ }^{1}$ Department of Electrical and Computer Engineering, Akashi College of Technology, Akashi, Japan \\ ${ }^{2}$ Technical Education Support Center, Akashi College of Technology, Akashi, Japan \\ ${ }^{3}$ Collaborative Laboratories for Advanced Decommissioning Science, Japan Atomic Energy Agency, Ibaraki, Japan \\ Email: ohmukai@akashi.ac.jp
}

How to cite this paper: Ohmukail, M., Nakagawa, T. and Matsumoto, A. (2017) ZnO Films Deposited on Porous Silicon by DC Sputtering. Journal of Materials Science and Chemical Engineering, 5, 12-20. https://doi.org/10.4236/msce.2017.56002

Received: May 3, 2017

Accepted: June 9, 2017

Published: June 12, 2017

Copyright (ङ 2017 by authors and Scientific Research Publishing Inc. This work is licensed under the Creative Commons Attribution International License (CC BY 4.0).

http://creativecommons.org/licenses/by/4.0/

\begin{abstract}
$\mathrm{ZnO}$ is now a fascinating semiconductor oxide material for light emission or transparent electronic conductors. We deposited $\mathrm{ZnO}$ films on porous silicon, which is known as a light emitting material based on silicon, by means of a direct current sputtering technique. The deposition was performed at room temperature, and the samples were annealed afterwards to improve the $\mathrm{ZnO}$ crystalline quality. The discussion to compare our results with that formed on $\mathrm{Si}$ wafer, reveals that the $\mathrm{ZnO}$ on porous silicon has the better crystalline quality in the scope of an X-ray diffraction measurement.
\end{abstract}

\section{Keywords}

ZnO Film, DC Sputtering, Annealing, X-Ray Diffraction Analysis, Porous Silicon

\section{Introduction}

$\mathrm{ZnO}$ attracts much attention [1]-[8] as a light emitting material or a transparent electronic conducting material. It is generally challenging to form compound semiconductor because the control of both elemental ratio and structural defects is inevitable. Nowadays, various deposition techniques have been applied to deposit $\mathrm{ZnO}$ films: radio frequency (RF) sputtering [9] [10], molecular beam epitaxy [11] [12], pulsed laser deposition [13] [14] and chemical vapor decomposition [15] [16]. Especially we have been challenging the deposition using a direct current (DC) sputtering technique [17]-[23] that is not used so often for oxide material. It was reported that the post-deposition annealing can well enhance the crystalline quality of $\mathrm{ZnO}$ both on the $\mathrm{Si}$ and glass substrates.

Porous silicon has a long history of its development. The remarkable issue is 
found in 1990: visible photoluminescence even observed by naked eye. The strong photoluminescence is fascinating because silicon is an indirect transition semiconductor and so light emission had not been thought to occur to such an extent. The emission from porous silicon is usually observed in the red or infrared region [24] [25]. The blue photoluminescence has been also reported from porous silicon, but it derives from silicon oxide formed on the surface of porous silicon. The electroluminescence has been also observed so far. It costs so little to form porous silicon where the relatively low reproducibility is, on the other hand, a big obstacle to make use of porous silicon as a commercial device.

$\mathrm{ZnO}$ has a wide direct band gap of $3.37 \mathrm{eV}$ and a large exciton binding energy of $60 \mathrm{meV}$ [26]. So $\mathrm{ZnO}$ has the ability to emit light in a blue or ultraviolet region. If $\mathrm{ZnO}$ is deposited on porous silicon, both blue and red light are supposed to be generated and combined. Actually Kayahan reported white light luminescence from $\mathrm{ZnO}$ deposited on porous silicon. Their interest was mainly focused on the luminescence. They showed X-ray diffraction pattern just for the purpose of monitor $\mathrm{ZnO}$ crystals.

In this article, we study the $\mathrm{ZnO}$ film quality with regard to an $\mathrm{X}$-ray diffraction pattern, if it is deposited on porous silicon. Our discussion will address to the comparison with the $\mathrm{ZnO}$ film on silicon wafer reported before. Porous silicon is a kind of disorder system in itself, and therefore the $\mathrm{ZnO}$ state on porous silicon is not clarified yet. In order to obtain basic information about $\mathrm{ZnO}$ structure, we investigated X-ray diffraction spectra from $\mathrm{ZnO}$ deposited on porous silicon closely.

\section{Experimental Details}

We prepared two kinds of porous silicon. We used (100) boron-doped p-type silicon wafer with a resistivity between 1 and $10 \Omega \cdot \mathrm{cm}$ for both kinds of porous silicon samples. A Si wafer (anode) and a Pt counter electrode (cathode) were installed in an electrolyte. An anodization of $\mathrm{Si}$ wafer was done at the current density of $20 \mathrm{~mA} / \mathrm{cm}^{2}$. The anodized area is just less than $2 \mathrm{~cm}^{2}$. The other condition is different in the two kinds of samples. One is formed in the most wellknown procedure. The electrolyte consists of HF (50 wt\%):ethanol $=1: 1$ (volume ratio) and anodization time was $30 \mathrm{~min}$. for one kind of sample (S1). For the other sample (S2), the electrolyte consists of $\mathrm{HF}(50 \mathrm{wt} \%): \mathrm{H}_{2} \mathrm{O}=1: 4$ (volume ratio) and anodization time was $5 \mathrm{~min}$. The latter anodization condition is not as popular as the former one. The appearance of the anodized surface is quite different as shown in the next section. The photoluminescence was checked only by naked eye using a handy mercury UV lamp for the excitation.

The obtained porous silicon samples were used as a substrate, and $\mathrm{ZnO}$ was deposited onto it. We used a $\mathrm{ZnO}$ ceramic target disk (4N) with $70 \mathrm{~mm}$ in diameter. The target was situated at a distance of $30 \mathrm{~mm}$ from the porous silicon substrate. The deposition was performed for five hours under the ambient pressure of $7.5 \mathrm{~Pa}$ and input power of $24 \mathrm{~W}$. The substrate was not intentionally heated during the deposition. After the deposition, annealing was performed by 
an electric furnace at $950^{\circ} \mathrm{C}$ for an hour in the air. The annealing condition is the same as the report by Kayahan.

The obtained samples were examined by means of an X-ray diffraction (XRD) measurement. The XRD pattern was taken with a spectrometer (Ultima IV, Rigaku) equipped with a $\mathrm{Cu}$ target and a $\mathrm{Ni}$ filter. X-ray tube was loaded with 40 $\mathrm{kV}$ and $40 \mathrm{~mA}$ in the experiment. The surfaces of the samples were observed by a scanning electron microscope (SEM) of JSM-6510LA by JEOL Ltd.

\section{Results}

The appearance of the porous silicon is shown in Figure 1. Both samples show the circular porous silicon region that can be clearly recognized. The appearance is quite different: S1 has a dark brownish color uniformly and S2 has a yellowish spotted pattern. The diameter of the circle is about $1 \mathrm{~cm}$. In this photograph, slight photoluminescence of orange color is seen near the periphery of the circle area because of the white light irradiation for taking a photograph. Figure 2 shows the photoluminescence irradiated with a UV lamp. The photoluminescence intensity is distinctly stronger in S2 for visible light.

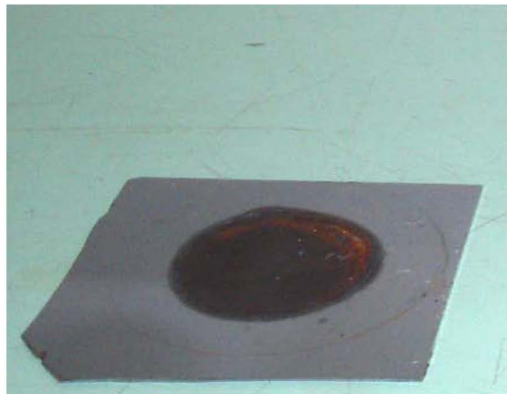

S1
S2

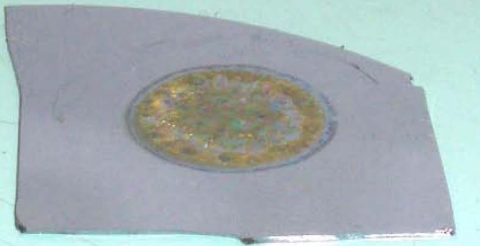

S2

Figure 1. The optical photographs of the two kinds of samples. Inside the central circular area, porous silicon is formed on the surface.

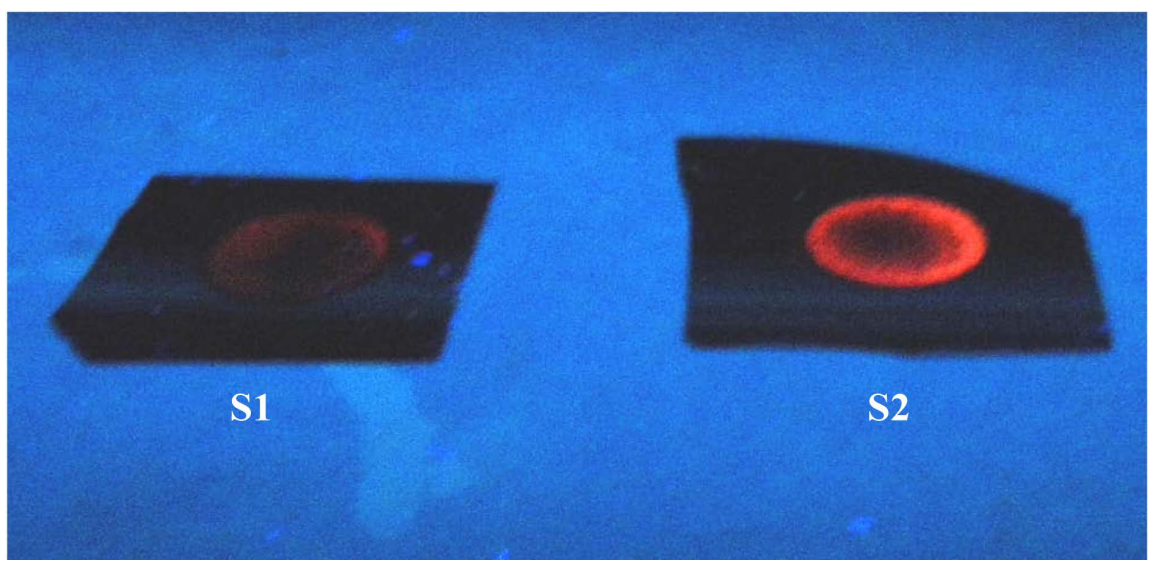

Figure 2. The optical photographs of the two kinds of samples excited with a mercury lamp. 
The SEM photographs taken from S1 and S2 samples are shown in Figure 3 and Figure 4, respectively. Figure 3 was taken from 65 degree to the normal direction, and shows the surface in the upper side and the cross section in the lower side. The white part at the most upper layer that is seen white in the figure corresponds to the $\mathrm{ZnO}$ layer: the cross sectional image of several $\mu \mathrm{m}$ in thickness and the surface area. Under $\mathrm{ZnO}$ layer, we can observe obvious two layers of porous silicon layer (middle) and silicon substrate layer (bottom). The obtained $\mathrm{ZnO}$ layer has a smooth and uniform structure. The SEM photo of the sample S2 in Figure 4 shows island structure of porous silicon surface. The edges at all islands show doubled lines, which indicate that the porous silicon islands are capsulated with $\mathrm{ZnO}$ films.

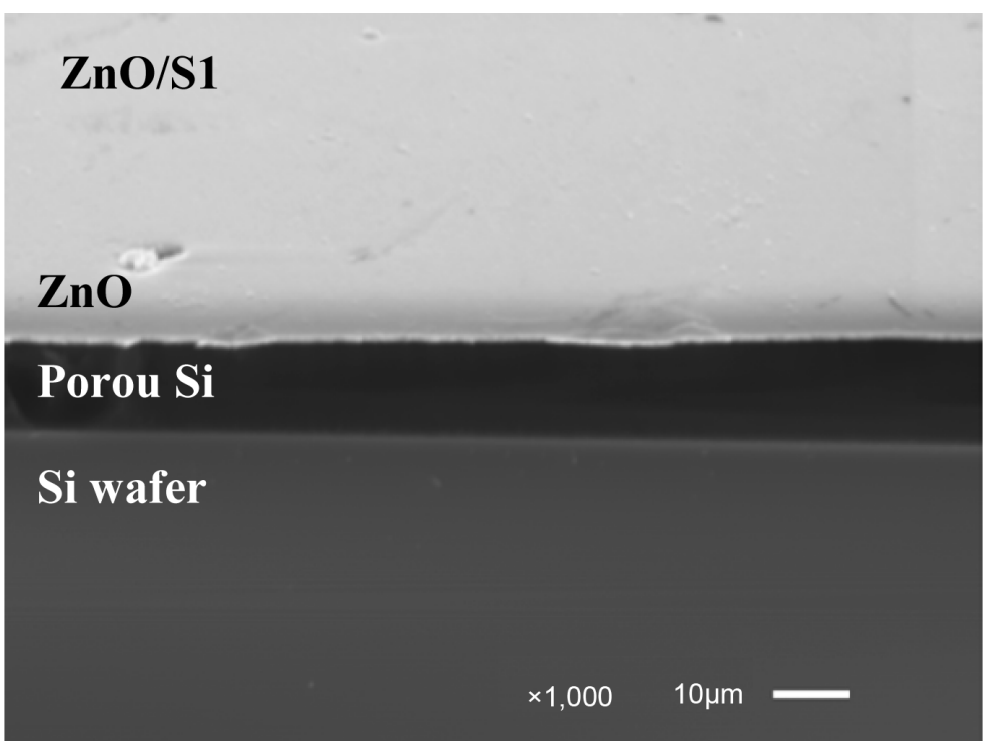

Figure 3. The SEM photographs of the sample S1: surface (upper) and cross section (lower).

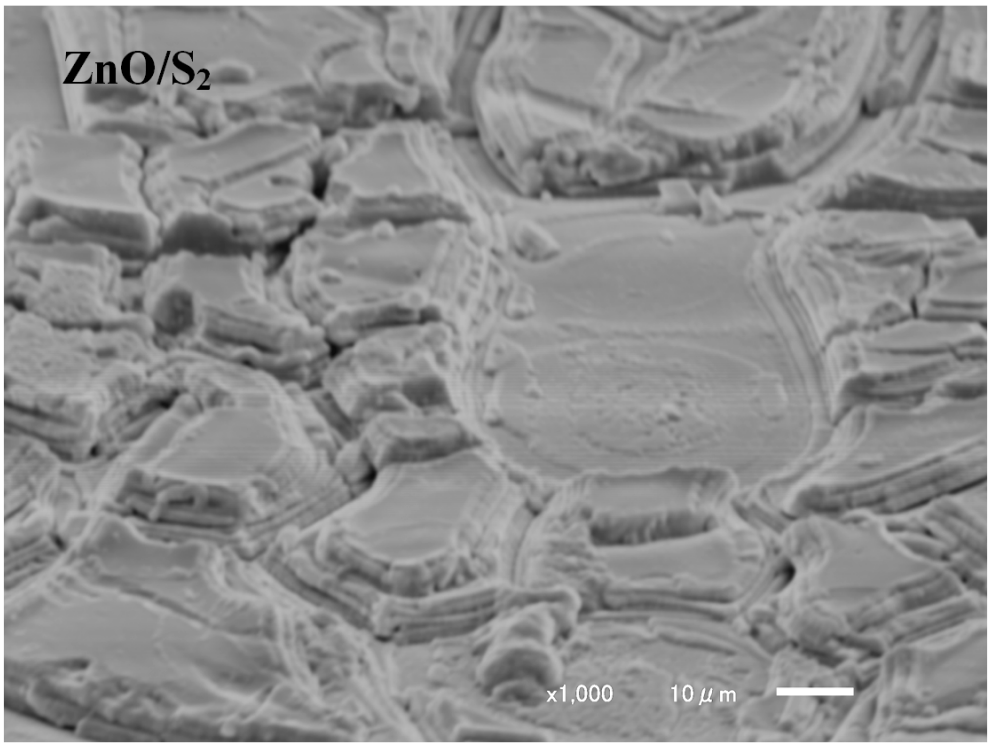

Figure 4. The SEM photographs of the sample S2 (surface). 
The $\mathrm{XRD}$ patterns taken from $\mathrm{ZnO} / \mathrm{S} 1$ and $\mathrm{ZnO} / \mathrm{S} 2$ are shown in Figure 5 and Figure 6, respectively. These patterns do not include the reflection from the substrates because the $\mathrm{ZnO}$ film was thick enough. Both figures consist of two patterns: as deposited sample (bottom) and annealed sample (top). In both figures, the pattern from the annealed samples consists of 5 structures diffracted from (100), (002), (101), (102) and (110) crystalline planes. As-deposited samples show only (002) diffraction that is broader and shifted to the lower $2 \theta$ side compared with that of annealed samples.

\section{Discussion}

According to the XRD data for $\mathrm{ZnO}$ (JCPDS data) tells us that the diffraction from (101) plane is the strongest. Contrary to the data, (002) diffraction is the strongest in both samples. It stems from the fact that the deposited $\mathrm{ZnO}$ film is preferentially oriented along to (101). The preference is stronger in the $\mathrm{ZnO} / \mathrm{S} 1$ sample.

We reported on the $\mathrm{ZnO}$ film deposited on Si substrate [23] and glass sub

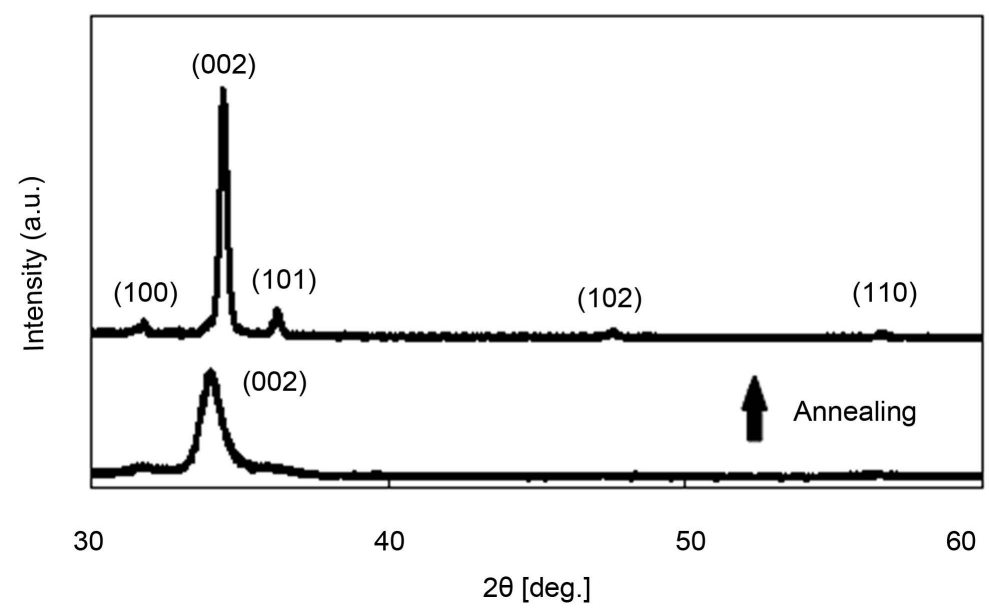

Figure 5. The XRD patterns taken from the sample S1.

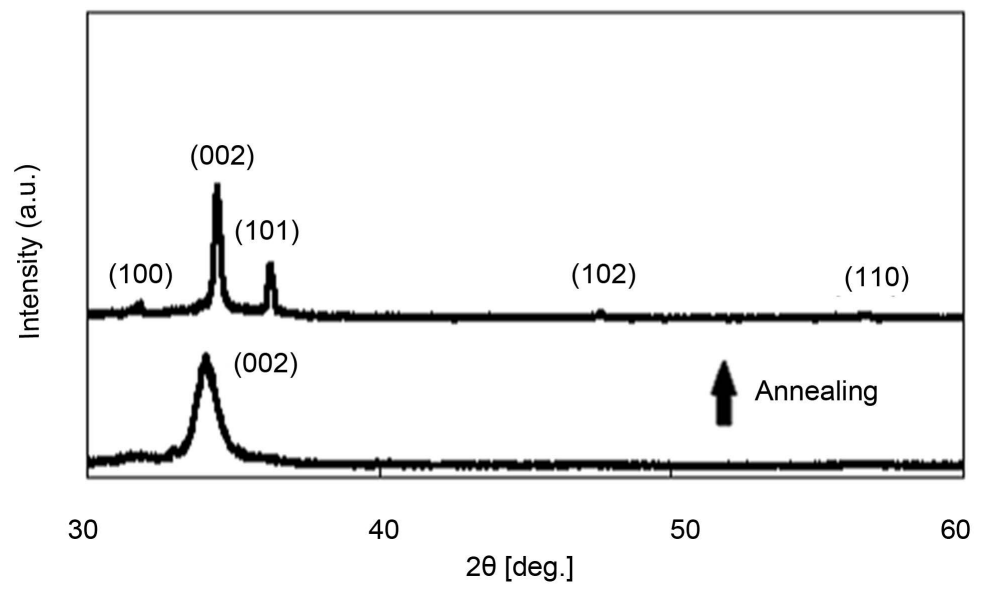

Figure 6. The XRD patterns taken from the sample S2. 
strate [27]. As-deposited sample has shown only (002) diffraction in both cases, similar to the results above. And then, the both samples, after annealed, have also shown only one structure corresponding to (002) diffraction without any other structures. However the $\mathrm{ZnO}$ deposited on porous silicon have shown the occurrence of the other four orientations by the annealing. The reason for the occurrence may be due to the surface structure of porous silicon, which does not have a smooth surface but a numerous pits or holes at a nano scale region. It allows a variety of crystal orientations of growing. Figure 4 shows the obvious bumpy surface of many terraces. It is easily understood from the point of view. On the other hand, Figure 3 shows a smooth surface apparently, but the annealing effect was different compared with the sample on Si wafer or glass substrates. It derives from the nanostructures of porous silicon that cannot be observed SEM photographs in the figures here.

We discuss here the (002) peak structure quantitatively comparing four samples with each other. The full width at half maximum (FWHM) of the peak corresponding to the (002) diffraction is considered here. Table 1 shows those of $\mathrm{ZnO} / \mathrm{S} 1$ and $\mathrm{ZnO} / \mathrm{S} 2$ as well as $\mathrm{ZnO} / \mathrm{Si}$ and $\mathrm{ZnO}$ /glass reported in the literature. The table shows the data both before and after the annealing. The annealing condition for $\mathrm{ZnO} /$ glass is $600^{\circ} \mathrm{C}$ and 0.5 hours, which is different from the others $\left(950^{\circ} \mathrm{C}\right.$ and 1 hour). It was because the glass cannot endure and melt above $600^{\circ} \mathrm{C}$. In all cases, the FWHM was reduced by the annealing. It is well accepted that the deposited $\mathrm{ZnO}$ restores from the crystallographic view by the annealing. In addition, Figure 3 and Figure 4 show that all samples before annealing have a slight shift to the lower angle side. This means the $\mathrm{ZnO}$ has tensile stress normal to the surface. In other words, compressive stress exists along the surface. Summarizing the above, the as-deposited $\mathrm{ZnO}$ film includes a uniform strain and non-uniform compressive stress, eased by the successive annealing.

For the as-deposited, all samples showed (002) reflection peaks regardless of the substrates. It is quite attractive phenomenon. The fact indicates that the very initial procedure of deposition is presumed to be the same. The (002) orientation is surely preferred to be grown even if the surface is rough at the nano scale. This can be related to a deposition mechanism of $\mathrm{ZnO}$.

Interesting point is the difference among the samples. The annealing condition is peculiar for $\mathrm{ZnO} /$ glass, so the other three kinds of samples are compared here. The peak position before the annealing and the shift amount by the annealing is quite similar for the three kinds of samples. The peak at $34.0^{\circ}$ or $34.1^{\circ}$ is shifted to $34.5^{\circ}$ in all cases. Contrarily, the FWHM of the peak does not show the same value. As-deposited sample shows the largest FWHM for $\mathrm{ZnO} / \mathrm{S} 2$ and then $\mathrm{ZnO} / \mathrm{S} 1$ and $\mathrm{ZnO} / \mathrm{Si}$ to become smaller. It is assumed that the uniform

Table 1. The FWHM's of samples before and after annealing.

\begin{tabular}{ccccc}
\hline Degree & $\mathrm{ZnO} / \mathrm{S} 1$ & $\mathrm{ZnO} / \mathrm{S}_{2}$ & $\mathrm{ZnO} / \mathrm{Si}$ & $\mathrm{ZnO} / \mathrm{Glass}$ \\
\hline Before & 0.801 & 0.825 & 0.725 & 0.91 \\
After & 0.24 & 0.187 & 0.262 & 0.798 \\
\hline
\end{tabular}


strain is the biggest for $\mathrm{ZnO} / \mathrm{S} 2$ because the $\mathrm{ZnO} / \mathrm{S} 2$ has the roughest surface in the three. However, this tendency is turned over by the annealing. Surprisingly $\mathrm{ZnO} / \mathrm{Si}$ has the largest FWHM and then $\mathrm{ZnO} / \mathrm{S} 1$ and $\mathrm{ZnO} / \mathrm{S} 2$. The FWHM of the peak is the narrowest for $\mathrm{ZnO} / \mathrm{S} 2$ after the annealing. It suggests that the $\mathrm{ZnO} / \mathrm{S} 2$ has the least strains in the film, even compared with $\mathrm{ZnO}$ on a Si single crystalline wafer. It leads to the conclusion that an S2 type of the substrate is helpful for growing a $\mathrm{ZnO}$ film with less uniform strain inside the film. This is also supported by the FWHM of the (101) diffraction peak. After the annealing, the values for $\mathrm{ZnO} / \mathrm{Si}$ and $\mathrm{ZnO} / \mathrm{S}_{2}$ are $0.221^{\circ}$ and $0.165^{\circ}$, respectively. The reason why rougher surface of $\mathrm{S} 2$ can provide better $\mathrm{ZnO}$ crystal is the next interesting point.

\section{Conclusion}

$\mathrm{ZnO}$ films were deposited onto porous silicon by a DC sputtering method and investigated mainly by means of XRD measurements. Two kinds of porous silicon were engaged in this research. One was formed by the anodization with an electrolyte including ethanol (S1), and the other without ethanol (S2). The surface morphology is quite different in the two: $\mathrm{S} 1$ looks apparently smooth by the SEM observation while S2 obviously consists of many terrace-like structures and then rough surface in the same-scale view. As-deposited $\mathrm{ZnO}$ films are oriented along (002) on the surface in both cases. The FWHMs of the (002) diffraction peaks are broader than that of $\mathrm{ZnO}$ deposited on single crystal Si wafer, and sharper than that of $\mathrm{ZnO}$ deposited on a glass substrate. The $\mathrm{S} 2$ sample provided broader peak than the S1 sample. The peak shift away from the JCPDS data is very similar in all four cases. Annealing enhanced the crystalline quality; the FWHMs were sharpened and the peak shift was eliminated. At the same time, (100), (101), (102) and (110) diffraction peaks for $\mathrm{ZnO}$ appeared from the S1 and S2 samples, which do not appear from $\mathrm{ZnO}$ on Si wafer. Further, the interesting point is that the FWHM of the (002) peaks after annealing was narrower compared with $\mathrm{ZnO}$ on $\mathrm{Si}$ wafer. And the S2 sample that has a rougher surface indicated a narrower (002) peak than the S1 sample. The $\mathrm{ZnO}$ film with high crystalline quality can be formed on porous silicon formed especially in an ethanol-less electrolyte.

\section{References}

[1] Galli, G. and Coker, J.E. (1970) Epitaxial ZnO on Sapphire. Applied Physics Letters, 16, 439-441. https://doi.org/10.1063/1.1653058

[2] Look, D.C. and Hemsky, J.W. (1999) Residual Native Shallow Donor in ZnO. Physical Review Letters, 82, 2552-2555. https://doi.org/10.1103/PhysRevLett.82.2552

[3] Zhang, S.B., Wei, S.-H. and Zunger, A. (2001) Intrinsic $n$-Type versus $p$-Type Doping Asymmetry and the Defect Physics of ZnO. Physical Review B, 63, Article No: 075205.

[4] Srikant, V. and Clarke, D.R. (1998) On the Optical Band Gap of Zinc Oxide. Journal of Applied Physics, 83, 5447-5451. https://doi.org/10.1063/1.367375

[5] Klaus, E., Andreas, K. and Bernd, R. (2008) Transparent Conductive Zinc Oxide. 
Springer Berlin Heidelberg, Berlin/Heidelberg.

[6] Sang, B., Dairiki, K., Yamada, A. and Konagai, M. (1999) High-Efficiency Amorphous Silicon Solar Cells with $\mathrm{ZnO}$ as Front Contact. Japanese Journal of Applied Physics, 38, 4983-4988. https://doi.org/10.1143/JJAP.38.4983

[7] Pearton, S.J., Abernathy, C.R., Thaler, G.T., Frazier, R.M., Norton, D.P., Ren, F., Park, Y.D., Zavada, J.M., Buyanova, I.A., Chen, W.M. and Hebard, A.F. (2004) Wide Bandgap GaN-Based Semiconductors for Spintronics. Journal of Physics. Condensed Matter, 16, R209-R245. https://doi.org/10.1088/0953-8984/16/7/r03

[8] Bang, S., Lee, S., Park, J., Park, S., Ko, Y., Choi, C., Chang, H., Park, H. and Jeon, H. (2011) The Effects of Post-Annealing on the Performance of ZnO Thin Film Transistors. Thin Solid Films, 519, 8109-8113. https://doi.org/10.1016/j.tsf.2011.05.048

[9] Yue, H., Wu, A., Feng, Y., Zhang, X. and Li, T. (2011) Structures and Properties of the Al-Doped ZnO Thin Films Prepared by Radio Frequency Magnetron Sputtering. Thin Solid Films, 519, 5577-5581. https://doi.org/10.1016/j.tsf.2011.03.026

[10] Furuta, M., Hiramatsu, T., Matsuda, T., Furuta, H. and Hirao, T. (2007) Effect of Energetic Particle Bombardment on Microstructure of Zinc Oxide Films Deposited by RF Magnetron Sputtering. Japanese Journal of Applied Physics, 46, 4038-4041. https://doi.org/10.1143/JJAP.46.4038

[11] Look, D.C., Reynolds, D.C., Litton, C.W., Jones, R.L., Eason, D.B. and Cantwell, G. (2002) Characterization of Homoepitaxial $p$-Type $\mathrm{ZnO}$ Grown by Molecular Beam Epitaxy. Applied Physics Letters, 81, 1830. https://doi.org/10.1063/1.1504875

[12] Kim, M.S., Kim, D.Y., Cho, M.Y., Nam, G., Kim, S., Lee, D.-Y., Kim S.-O. and Leem, J.-Y. (2012) Effects of Buffer Layer Thickness on Properties of ZnO Thin Films Grown on Porous Silicon by Plasma-Assisted Molecular Beam Epitaxy. Vacuum, 86, 1373-1379. https://doi.org/10.1016/j.vacuum.2012.01.006

[13] Craciun, V., Elders, J., Gardeniers, J.G.E. and Boyd, I.W. (1994) Characteristics of High Quality ZnO Thin Films Deposited by Pulsed Laser Deposition. Applied Physics Letters, 65, 2963-2965. https://doi.org/10.1063/1.112478

[14] Chirakkara, S. and Krupanidhi, S.B. (2012) Study of n-ZnO/p-Si (100) Thin Film Heterojunctions by Pulsed Laser Deposition without Buffer Layer. Thin Solid Films, 520, 5894-5899. https://doi.org/10.1016/j.tsf.2012.05.003

[15] Ataev, B.M., Bagamadova, A.M., Mamedov, V.V. and Omaev, A.K. (1999) Thermally Stable, Highly Conductive, and Transparent ZnO Layers Prepared in Situ by Chemical Vapor Deposition. Materials Science and Engineering: B, 65, 159-163. https://doi.org/10.1016/S0921-5107(99)00166-X

[16] Xie, Y., Madel, M., Zoberbier, T., Reiser, A., Jie, W., Neuschl, B., Biskupek, J., Kaiser, U. ,Feneberg, M. and Thonke, K. (2012) Enforced c-Axis Growth of ZnO Epitaxial Chemical Vapor Deposition Films on a-Plane Sapphire. Applied Physics Letters, 100, Article ID: 182101. https://doi.org/10.1063/1.4709430

[17] Ahmad, A. and Alsaad, A. (2006) Optical Properties of ZnO Related to the DC Sputtering Power. The European Physical Journal B, 52, 41-46. https://doi.org/10.1140/epjb/e2006-00272-0

[18] Hata, T., Minamikawa, T., Morimoto, O. and Hada, T. (1979) DC Reactive Magnetron Sputtered ZnO Films. Journal of Crystal Growth, 47, 171-176. https://doi.org/10.1016/0022-0248(79)90239-2

[19] Suchea, M., Christoulakis, S., Katsarakis, N., Kitsopoulos, T. and Kiriakidis, G. (2007) Comparative Study of Zinc Oxide and Aluminum Doped Zinc Oxide Transparent Thin Films Grown by Direct Current Magnetron Sputtering. Thin Solid Films, 515, 6562-6566. https://doi.org/10.1016/j.tsf.2006.11.151 
[20] Lee, J., Kim, Y., Song, P., Lee, J., Kim, Y. and Son, C. (2008) Characteristic of Ga-Doped ZnO Films Deposited by DC Magnetron Sputtering with a Sintered Ceramic ZnO:Ga Target. Journal of the Korean Physical Society, 53, 416-420.

[21] Abduev, A., Akhmedov, A., Asvarov, A. and Abdullaev, A. (2008) Investigations of Synthesis Mechanisms of $\mathrm{ZnO}$ Thin Films in DC Magnetron Sputter Processes. Journal of the Korean Physical Society, 53, 59-62.

[22] Quemener, V., Vines, L., Monakhov, E.V. and Svensson, B.G. (2011) Electronic Properties of $\mathrm{n}-\mathrm{ZnO}(\mathrm{Al}) / \mathrm{p}-\mathrm{Si}$ Heterojunction Prepared by DC Magnetron Sputtering. Thin Solid Films, 519, 5763-5766. https://doi.org/10.1016/j.tsf.2010.12.204

[23] Ohmukai, M., Nakagawa, T. and Matsumoto, A. (2015) Oxygen Surplus to Zn in $\mathrm{ZnO}$ Films Deposited by Means of Direct Current Sputtering. Journal of Nanoelectronics and Optoelectronics, 10, 65-68.

[24] Ohmukai, M. and Tsutsumi, Y. (1998) Relaxation Process of Excited Carriers in Luminescent and Nonluminescent Porous Silicon. Journal of Applied Physics, 84, 4459. https://doi.org/10.1063/1.368670

[25] Ohmukai, M., Muaki, H. and Tsutsumi, Y. (2002) Two Kinds of Enhancement in Photoluminescence by Chemical Etching of Porous Silicon. Materials Science and Engineering: B, 95, 287-289. https://doi.org/10.1016/S0921-5107(02)00288-X

[26] Ozaki, K. and Gomi, M. (2002) Strong Ultraviolet Photoluminescence in Polycrystalline ZnO Sputtered Films. Japanese Journal of Applied Physics, 41, 5614-5617. https://doi.org/10.1143/JJAP.41.5614

[27] Ohmukai, M., Nakagawa, T. and Matsumoto, A. (2016) AnO Films Deposited on Glass by Means of DC Sputtering. Journal of Materials Science and Chemical Engineering, 4, 1-7.

\section{Submit or recommend next manuscript to SCIRP and we will provide best service for you:}

Accepting pre-submission inquiries through Email, Facebook, LinkedIn, Twitter, etc. A wide selection of journals (inclusive of 9 subjects, more than 200 journals)

Providing 24-hour high-quality service

User-friendly online submission system

Fair and swift peer-review system

Efficient typesetting and proofreading procedure

Display of the result of downloads and visits, as well as the number of cited articles

Maximum dissemination of your research work

Submit your manuscript at: http://papersubmission.scirp.org/

Or contact msce@scirp.org 